\title{
The Metabolic Syndrome - A Global Challenge for Prevention
}

Author

Affiliation

\author{
P. E. H. Schwarz ${ }^{1}$, M. Reimann' ${ }^{1}$ J. Li' , A. Bergmann' , J. Licinio², M.-L. Wong², S. R. Bornstein
}

${ }^{1}$ Department of Internal Medicine III, Clinic for Endocrinology, Diabetes and Metabolism, Technical University Dresden, Medical Faculty Carl Gustav Carus, Dresden, Germany

${ }^{2}$ Department of Psychiatry \& Behavioural Sciences, University of Miami Miller School of Medicine, Miami, FL, USA

Key words

metabolic syndrome

- global health

- prevention

- type 2 diabetes

- intervention received 20.08.2007

accepted 03.09.2007

\section{Bibliography}

DOI 10.1055/s-2007-990312

Horm Metab Res 2007;

39: 777-780

(c) Georg Thieme Verlag KG

Stuttgart · New York

ISSN 0018-5043

\section{Correspondence}

Dr. P. E. H. Schwarz

Division of Endocrinology

Department of Medicine III

Medical Faculty Carl-Gustav-

Carus

Technical University Dresden 01307 Dresden

Germany

Tel.: + 49/351/458 2715

Fax: $+49 / 351 / 4587319$

peter.schwarz@uniklinikum-

dresden.de

\section{Abstract \\ $\nabla$}

In the last years we have learned a lot about the pathopysiology of a cluster of the diseases called Metabolic Syndrome but currently an exciting discussion debates the Metabolic Syndrome in a light of a mystery of medicine or a clinical paradigm with a controversary about diagnostic, treatment or preventive procedure. There is now convincing evidence that prevention is the most important and effective way to reduce the personal and socio-economic burden of the Metabolic Syndrome and its associated complications.

\section{The global metabolic challenge}

Over the last 100 years, scientific innovation has led to a revolution in our understanding of the causes of chronic diseases and our ability to prevent and treat diseases [1,2]. This revolution has primarily improved health and well-being in industrialized countries. In developing countries, the situation is markedly different. Parallel with globalization pronounced changes in the human environment and in human behavior and lifestyle have resulted in escalating rates of both obesity and diabetes $[3,4]$. The more prevalent sedentary lifestyle and the globalization of "fast" and overly rich nutrition have promoted the development of risk factors for the Metabolic Syndrome and the development of diabetes [5]. The risk factors are well-known: obesity, visceral adiposity, physical inactivity, and unhealthy diet.

\section{Type 2 diabetes is an epidemic} $\nabla$

The dramatic increase in newly diagnosed cases of type 2 diabetes and its complications have developed into a major public health concern affecting nearly all populations in developed and
Still, it is currently not clear how to implement preventive interventions into clinical practice but will require an integrated and transdisciplinary approach on an international level in order to efficiently reduce premature morbidity and mortality. Nevertheless, global strategies are still lacking but are needed to tackle inequalities in health between industrialized countries and the developing world. A global health strategy has to take into account political, epidemiological, environmental, infrastructural and genetic aspects. The Metabolic Syndrome is not a mystery - it is a clinical paradigm and global challenge.

developing countries [6]. The global prevalence of type 2 diabetes is expected to double by the year 2025. Patients with type 2 diabetes are at increased risk of cardiovascular disease (coronary heart disease and stroke), which is the principle cause of death, disability, and excess health care costs in diabetes. The patients with diabetes are more likely to die from cardiovascular events at its first event than their nondiabetic counterparts. Thus early diagnosis and prevention of type 2 diabetes may prevent its costly complications, i.e., cardiovascular and renal diseases.

\section{Type $\mathbf{2}$ diabetes as part of the metabolic cluster $\nabla$}

For the last 50 years we have observed an increasing prevalence of a cluster of diseases - obesity, type 2 diabetes, hypertension, and dyslipidemia which are closely interrelated and strongly depend on environmental factors $[7,8]$. The association of type 2 diabetes and cardiovascular disease has led to the hypothesis that both arise from common antecedent or common factors like insulin resistance, obesity, dyslipidemia, hypertension etc., since the latter rarely occur isolated in our patients. 
Based on extensive pathophysiological clinical and epidemiological investigations, the paradigm of the Metabolic Syndrome was developed and first published in a comprehensive review in 1981 [9], which is a source of constant controversial discussion on the pathophysiology, the relevance of traits, and cutoff limits for obesity and the Metabolic Syndrome up to the present day. Later Gerald Reaven described this cluster of diseases in 1988 as Syndrome X, and proposed that hyperinsulinemia is the pathological interface between the distinct components and the Metabolic Syndrome [10]. Later, the World Health Organization (WHO) modified this concept as Metabolic Syndrome and proposed a definition which states that a person has the Metabolic Syndrome if he or she has diabetes, impaired glucose tolerance, impaired fasting glucose or insulin resistance, plus two or more of the following abnormalities: high blood pressure, high triglycerides and low HDL cholesterol, increased waist/hip ratio, increased urinary albumin excretion rate, or increased albumin/ creatinine ratio [11]. One of the relevant problems regarding this definition was that there is no simple clinically applicable test for insulin resistance. In addition the third report of the National Cholesterol Education Program expert panel on detection, evaluation, and treatment of high blood cholesterol in adults (ATPIII) proposed a new working definition of Metabolic Syndrome in 2001 based upon anthropometric measurements, blood pressure and simple laboratory investigations like fasting blood glucose, triglycerides, and HDL-cholesterol which could easily be estimated [12]. Thus, ATPIII has considered the Metabolic Syndrome as coronary heart disease risk equivalent. In 2005 the International Diabetes Federation established its own definition of the Metabolic Syndrome. Accordingly, to be diagnosed with the Metabolic Syndrome a person must have central obesity, plus any two of the following four factors: (1) increased triglyceride level, or (2) low HDL cholesterol or specific treatment for lipid abnormality, or (3) high blood pressure or adequate treatment increased fasting plasma glucose, or (4) previously diagnosed type 2 diabetes $[13,14]$. The limiting step is that ethnic specific values for central obesity are not available for each population.

\section{Controversial pathophysiology \\ $\nabla$}

The Metabolic Syndrome is currently undergoing vivid exciting debates by discussing it in the light of a mystery of medicine or a clinical paradigm [8]. Recently, abnormalities in postprandial regulation in connection with the Metabolic Syndrome have become a hot topic in metabolic research [15-17]. There is now convincing evidence that the Metabolic Syndrome develops in conjunction with complex derangements in hormonal $[18,19]$ and metabolic regulation $[20,21]$. Central obesity has been labeled to be a precondition for the diagnosis of the Metabolic Syndrome by the IDF. Visceral obesity together with insulin resistance and low grade inflammation seem to provide the foundation for the development of type 2 diabetes and atherosclerotic vascular disease. Furthermore, food intake leads to a complex immune response which may activate low grade inflammation [22]. Summarizing the current discussion, the Metabolic Syndrome is seen as endocrine [23], nutritional [24], cardiovascular, metabolic [25], behavioral [26-28], and ethnicity driven disease [29] as well as in its preventive aspects. This fruitful discussion about the Metabolic Syndrome has just started calling for a clearer and global definition taking ethnic differences into account.

\section{The Metabolic Syndrome can be prevented \\ $\nabla$}

The Metabolic Syndrome is becoming a global challenge. The most efficient way to manage the Metabolic Syndrome and its complications is to prevent it from developing [3]. Currently, numerous prevention and disease management concepts exist worldwide which can be implemented into clinical practice [30]. Most of the evidence regarding the prevention of the Metabolic Syndrome derives from the diabetes preventions studies.

Several studies have convincingly demonstrated that prevention of type 2 diabetes is possible. The best approach for preventing diabetes is still not clear, but there is overwhelming evidence that up to $60 \%$ of new developing diabetes can be prevented or delayed through lifestyle modification and/or pharmacological interventions in high risk individuals [31-34]. These studies have showed in the past years that lifestyle intervention, addressing diet and exercise, could reduce the risk of progressing from impaired glucose tolerance (IGT) to diabetes by 43 and $58 \%$, whereas the oral hyperglycemic drug metformin reduced the risk by $31 \%$ only [31]. The preventive intervention seems to be more effective in elderly and obese [31,32]. Furthermore it was shown that acarbose [33], troglitazone [35] and orlistat [36] significantly decreased progression of impaired glucose tolerance to diabetes. These findings were recently confirmed by the Indian Diabetes Prevention Program (IDPS) [37]. By extrapolating these data to the European population we can expect a 50$60 \%$ reduction in the diabetes risk - if we are able to implement efficient diabetes prevention programs [30]. While these findings offer the evidence-base for the development of community-based prevention strategies, it is necessary to learn how the prevention of T2D works in "the real world" [38].

\section{What are management aims in the prevention of the Metabolic Syndrome? \\ $\nabla$}

With a better understanding of the pathogenesis of the Metabolic Syndrome, the concept of primary prevention has emerged and we have overwhelming evidence that we can prevent or delay the progression of the syndrome [39]. Prevention of the disease is our only chance to alleviate the ever growing burden of diabetes mellitus. By knowing this, our first aim is to reduce the incidence of diabetes among those who are at high risk or having the Metabolic Syndrome. Further, the effect should be maintained over a long time, and this should ultimately reduce the associated burden of the disease in terms of micro- and macrovascular complications.

To achieve these goals it is necessary to answer the following questions: 1. How do people with the Metabolic Syndrome receive the necessary information and motivation to change lifestyle - and what intervention is the best one? 2 . What is the best way to maintain lifestyle changes over a long time [30] and how can we manage and control the quality of the intervention? Additionally, the potential intervention should be accessible to the general population on a national level calling attention to people at risk for diabetes. Furthermore, it is necessary to take into consideration the health care and reimbursement system 
and issues of professionalism - to decide who is the professional to carry out the lifestyle intervention $[30,40]$.

It is unrealistic to believe that the increasing trend in the prevalence of diabetes can be reduced by focusing solely on high risk subjects. A feasible model of action is a program that achieves a proportionally slower diabetes incidence over time and able to maintain metabolic changes after discontinuation of the intervention [38]. In addition, a population strategy aiming at the promotion of health addressing healthy diet and physical activity is required to reduce the number of high risk subjects most likely to develop diabetes.

\section{How to control the quality of the intervention? $\nabla$}

The key factors in performing high quality intervention are continuous evaluation and quality control [41]. Therefore, a continuous system of quality management and reporting needs to be established. This can become a key criterion for the success or failure of the intervention. One option is the long term measurement of blood pressure and waist circumference to be chosen for quality control and an independent evaluation. Prevention of the Metabolic Syndrome means reduction of risk factors like blood pressure and waist circumference. The latter were associated with the intervention effect in previous intervention studies. Monitored on a regular basis, both parameters may reflect changes in risk and lifestyle as induced by the intervention $[30,42]$. With such a procedure, a transparent feedback is possible both to the person receiving the intervention and the prevention manager. The advantage of the quality control is an early identification of nonresponders who can be quickly allocated for a booster intervention [30]. Furthermore, the evaluation of the mentioned parameters can be used to establish a "pay for performance" model [30].

\section{How to maintain the effect? \\ $\nabla$}

Several investigations in the past showed that time-limited interventions aiming to change lifestyle fail to reach a continuous lifestyle change $[30,38]$. It is a matter of human nature to be motivated at first but fail to maintain over long periods [3]. However, in the extended follow-up of the Finnish Diabetes Prevention Study, beneficial lifestyle changes and the corresponding reduction in diabetes risk were sustained over a long period of time [43-45]. The long term motivation to maintain lifestyle changes needs to be the main target of the prevention management concept. Therefore, after the initial intervention it is necessary to provide a regular contact scheme with at least monthly intervals to strengthen the motivation of the participating persons [30]. This can include written "newsletters", telephone counseling and booster, assisted problem management, continuous support including websites, regular interactive email newsletters, optional booster sessions, and assistance to explore the environment for physical activity [46]. Furthermore, regular quality control measurements are ideal for a personal feedback which should assist the individual in sustaining the achieved lifestyle change $[29,30]$.

\section{Conclusion}

$\checkmark$

Prevention is the only way to reduce the personal and socio-economic burden of the Metabolic Syndrome and its associated complications. The scientific evidence supporting primary prevention by lifestyle intervention and translations of study strategies into national prevention programs is compelling. Still, it is currently not clear how to implement these intervention methods. The successful implementation of prevention programs for the Metabolic Syndrome requires an integrated and transdisciplinary approach on an international level in order to efficiently reduce premature morbidity and mortality. We need to accept that the Metabolic Syndrome is not a disease; it is a symptom of a much larger problem - the adaptation of our metabolism to sedentary globalization [2]. Therefore, affordable strategies and quality controlled programs are needed for primary prevention. The health intervention may not only be focused to the Metabolic Syndrome but should also address diseases like cardiovascular disease, certain cancer types, and osteoporosis. Integration of lifestyle intervention into current health care systems will require a simple network of prevention managers and physicians to provide effective programs of lifestyle intervention and to implement quality controlled prevention strategies.

Nevertheless, global strategies are still lacking but are needed to tackle inequalities in health between industrialized countries and the developing world. A global health strategy has to take into account political, epidemiological, environmental, infrastructural, and genetic aspects [47-49]. The aim is to accomplish the greatest benefit with available resources on a long-term perspective.

The Metabolic Syndrome is not a mystery - it is a clinical paradigm and global challenge - we have to start to prevent it.

\section{References}

1 Bornstein SR, Wong ML, Licinio J. 150 years of Sigmund Freud: What would Freud have said about the obesity epidemic? Mol Psychiatry 2006; 11: 1070-1072

2 Hanefeld M, Ceriello A, Schwarz PE, Bornstein SR. The metabolic syndrome-a postprandial disease? Horm Metab Res 2006; 38: 435-436

3 Schwarz PE, Schwarz J, Bornstein SR, Schulze J. Diabetes preventionfrom physiology to implementation. Horm Metab Res 2006; 38 : 460-464

4 Korenblum W, Barthel A, Licinio J, Wong ML, Wolf OT, Kirschbaum C, Bornstein SR. Elevated cortisol levels and increased rates of diabetes and mood symptoms in Soviet Union-born Jewish immigrants to Germany. Mol Psychiatry 2005; 10: 974-975

5 Schwarz PE, Bornstein SR. Pre-diabetes and metabolic syndrome in Germans. Horm Metab Res 2006; 38: 359

6 Valensi P, Schwarz EH, Hall M, Felton AM, Maldonato A, Mathieu C. Pre-diabetes essential action: a European perspective. Diabetes Metab 2005; 31: 606-620

7 Schwarz PE. Report from the Congress of the American Diabetes Association (ADA): Orlando 2005 - 65th Annual Scientific Sessions in San Diego, CA, USA, June 10-14th 2005. Exp Clin Endocrinol Diabetes 2005; 113: 475-479

8 Schwarz PE. Congress report from the American Diabetes Association 66th Annual Scientific Sessions in Washington, USA. Exp Clin Endocrinol Diabetes 2006; 114: 605-610

9 Hanefeld M. LW. Das Metabolische Syndrom. Dtsch Gesundh Wesen 1981; 36: 545-551

10 Reaven GM. Banting lecture 1988. Role of insulin resistance in human disease. Diabetes 1988; 37: 1595-1607

11 World Health Organization. Definition, diagnosis and classification of diabetes mellitus and its complications. Report of a WHO Consultation 1999

12 Executive Summary of The Third Report of The National Cholesterol Education Program (NCEP) Expert Panel on Detection, Evaluation, And Treatment of High Blood Cholesterol In Adults (Adult Treatment Panel III). JAMA 2001; 285: 2486-2497 
13 Alberti KG, Zimmet $P$, Shaw J. International Diabetes Federation: a consensus on Type 2 diabetes prevention. Diabet Med 2007; 24: 451-463

14 Zimmet P, Magliano D, Matsuzawa Y, Alberti G, Shaw J. The metabolic syndrome: a global public health problem and a new definition. J Atheroscler Thromb 2005; 12: 295-300

15 Rudofsky Jr G, Reismann P, Schiekofer S, Petrov D, Eynatten M, Humpert PM, Isermann B, Muller-Hoff $C$, Thai TP, Lichtenstein $S$, Bartsch $U$, Hamann A, Nawroth $P$, Bierhaus A. Reduction of postprandial hyperglycemia in patients with type 2 diabetes reduces NF-kappaB activation in PBMCs. Horm Metab Res 2004; 36: 630-638

16 Haslbeck KM, Schleicher E, Bierhaus A, Nawroth P, Haslbeck $M$, Neundorfer $B$, Heuss $D$. The AGE/RAGE/NF-(kappa)B pathway may contribute to the pathogenesis of polyneuropathy in impaired glucose tolerance (IGT). Exp Clin Endocrinol Diabetes 2005; 113: 288-291

17 Schiekofer S, Franke S, Andrassy M, Chen J, Rudofsky G, Schneider JG, Eynatten $M$ von, Wendt $T$, Morcos $M$, Kientsch-Engel $R$, Stein $G$, Schleicher E, Nawroth PP, Bierhaus A. Postprandial mononuclear NFkappaB activation is independent of the AGE-content of a single meal. Exp Clin Endocrinol Diabetes 2006; 114: 160-167

18 Kamari Y, Grossman E, Oron-Herman M, Peleg E, Shabtay Z, Shamiss A, Sharabi $Y$. Metabolic stress with a high carbohydrate diet increases adiponectin levels. Horm Metab Res 2007; 39: 384-388

19 Kyrou I, Tsigos C. Stress mechanisms and metabolic complications. Horm Metab Res 2007; 39: 430-438

20 Schuppenies A, Schwarz P, Bornstein SR. Seasonal affective disorder and HPA axis disturbance. Horm Metab Res 2006; 38: 434

21 Ohmura E, Hosaka D, Yazawa M, Tsuchida A, Tokunaga M, Ishida $H$, Minagawa S, Matsuda A, Imai Y, Kawazu S, Sato T. Association of free fatty acids (FFA) and tumor necrosis factor-alpha (TNF-alpha) and insulin-resistant metabolic disorder. Horm Metab Res 2007; 39: 212-217

22 Schmitz G, Langmann T. Metabolic learning in the intestine: adaptation to nutrition and luminal factors. Horm Metab Res 2006; 38: 452-454

23 Ansurudeen I, Kopprasch S, Ehrhart-Bornstein M, Willenberg HS, Krug AW, Funk RH, Bornstein SR. Vascular-adrenal niche - endothelial cell-mediated sensitization of human adrenocortical cells to angiotensin II. Horm Metab Res 2006; 38: 476-480

24 Slama G, Elgrably F, Kabir M, Rizkalla SW. Role of low-glycemic-index foods in improving overall glycemic control in type 1 and type 2 diabetic patients and correcting excessive postprandial hyperglycemia. Horm Metab Res 2006; 38: 465-468

25 Pistrosch F, Koehler C, Wildbrett J, Hanefeld M. Relationship between diurnal glucose levels and HbA1c in type 2 diabetes. Horm Metab Res 2006; 38: 455-459

26 Lamounier-Zepter V, Ehrhart-Bornstein M, Bornstein SR. Metabolic syndrome and the endocrine stress system. Horm Metab Res 2006; 38: 437-441

27 Bornstein SR, Schuppenies A, Wong ML, Licinio J. Approaching the shared biology of obesity and depression: the stress axis as the locus of geneenvironment interactions. Mol Psychiatry 2006; 11: 892-902

28 Reichel A, Schwarz J, Schulze J, Licinio J, Wong ML, Bornstein SR. Depression and anxiety symptoms in diabetic patients on continuous subcutaneous insulin infusion (CSII). Mol Psychiatry 2005; 10: 975-976

29 Wenying $Y$, Zhaojun Y. Obesity and hypertension as two anthropometric predictors for metabolic syndrome. Horm Metab Res 2006; 38: 469-470

30 Schwarz PE, Schwarz J, Schuppenies A, Bornstein SR, Schulze J. Development of a diabetes prevention management program for clinical practice. Public Health Rep 2007; 122: 258-263

31 Knowler WC, Barrett-Connor E, Fowler SE, Hamman RF, Lachin JM, Walker $E A$, Nathan DM. Reduction in the incidence of type 2 diabetes with lifestyle intervention or metformin. N Engl J Med 2002; 346: 393-403

32 Tuomilehto J, Lindstrom J, Eriksson JG, Valle TT, Hamalainen H, IlanneParikka $P$, Keinanen-Kiukaanniemi $S$, Laakso $M$, Louheranta $A$, Rastas M, Salminen V, Uusitupa M. Prevention of type 2 diabetes mellitus by changes in lifestyle among subjects with impaired glucose tolerance. N Engl J Med 2001; 344: 1343-1350

33 Chiasson JL, Josse RG, Gomis R, Hanefeld M, Karasik A, Laakso M. Acarbose for prevention of type 2 diabetes mellitus: the STOP-NIDDM randomised trial. Lancet 2002; 359: 2072-2077
34 Pan XR, Li GW, Hu YH, Wang JX, Yang WY, An ZX, Hu ZX, Lin J, Xiao JZ, Cao HB, Liu PA, Jiang XG, Jiang YY, Wang JP, Zheng $H$, Zhang $H$, Bennett $P H$, Howard $B V$. Effects of diet and exercise in preventing NIDDM in people with impaired glucose tolerance. The Da Qing IGT and Diabetes Study. Diabetes Care 1997; 20: 537-544

35 Snitker S, Watanabe RM, Ani I, Xiang AH, Marroquin A, Ochoa $C$, Goico J, Shuldiner AR, Buchanan TA. Changes in insulin sensitivity in response to troglitazone do not differ between subjects with and without the common, functional Pro12Ala peroxisome proliferator-activated receptor-gamma2 gene variant: results from the Troglitazone in Prevention of Diabetes (TRIPOD) study. Diabetes Care 2004; 27: 1365-1368

36 Torgerson JS, Hauptman J, Boldrin MN, Sjostrom L. XENical in the prevention of diabetes in obese subjects (XENDOS) study: a randomized study of orlistat as an adjunct to lifestyle changes for the prevention of type 2 diabetes in obese patients. Diabetes Care 2004; 27 : 155-161

37 Ramachandran A, Snehalatha $C$, Mary S, Mukesh B, Bhaskar AD, Vijay $V$. The Indian Diabetes Prevention Programme shows that lifestyle modification and metformin prevent type 2 diabetes in Asian Indian subjects with impaired glucose tolerance (IDPP-1). Diabetologia 2006; 49: 289-297

38 Schwarz PEH, Schwarz J, Bornstein SR, Schulze J. Prevention of type 2 diabetes: what challenges do we have to address? J. Public Health 2005; 13: 303-308

39 Schwarz PE, Schuppenies A, Gruhl U, Hoffmann R, Bornstein SR, Schulze J, Landgraf R. Prevention of type 2 diabetes in Germany. Ideas, evidence, implementation. Med Klin (Munich) 2006; 101: 730-736

40 Schwarz P. Targeted diabetes prevention in high risk groups: pro. Dtsch Med Wochenschr 2005; 130: 1103

41 Roubideaux $Y$, Buchwald $D$, Beals J, Middlebrook D, Manson $S$, Muneta B, Rith-Najarian S, Shields R, Acton K. Measuring the quality of diabetes care for older american indians and alaska natives. Am J Public Health 2004; 94: 60-65

42 Schwarz PE, Bornstein SR, Hanefeld M. Elevated fasting glucose levels predicts IGT and diabetes also in middle-age subjects. Diabetes Res Clin Pract 2007; 77: 148-150

43 Lindstrom J, Ilanne-Parikka P, Peltonen M, Aunola S, Eriksson JG, Hemio K Hamalainen $H$, Harkonen $P$, Keinanen-Kiukaanniemi $S$, Laakso $M$, Louheranta A, Mannelin M, Paturi M, Sundvall J, Valle TT, Uusitupa M, Tuomilehto J. Sustained reduction in the incidence of type 2 diabetes by lifestyle intervention: follow-up of the Finnish Diabetes Prevention Study. Lancet 2006; 368: 1673-1679

44 Saaristo T, Peltonen M, Lindstrom J, Saarikoski L, Sundvall J, Eriksson JG, Tuomilehto J. Cross-sectional evaluation of the Finnish Diabetes Risk Score: a tool to identify undetected type 2 diabetes, abnormal glucose tolerance and metabolic syndrome. Diab Vasc Dis Res 2005; 2: 67-72

45 Schwarz PEH, Li J, Wegner H, Bornstein SR, Lindström J, Tuomilehto J. An accurate risk score based on anthropometric, dietary, and lifestyle factors to predict the development of type 2 diabetes, response to schulze et al. Diabetes Care 2007; 30: e87

46 Schwarz PE, Peltonen M. Prevention of Type 2 Diabetes - Lessons we have Learnt for Implementation. Horm Metab Res 2007; 39: 636641

47 Schwarz PE, Govindarajalu S, Towers W, Schwanebeck U, Fischer S Vasseur F, Bornstein SR, Schulze J. Haplotypes in the Promoter Region of the ADIPOQ Gene are Associated with Increased Diabetes Risk in a German Caucasian Population. Horm Metab Res 2006; 38: 447-451

48 Rudofsky Jr G, Schrodter A, Voron'ko OE, Schlotterer A, Humpert PM, Tafel J, Nawroth PP, Bierhaus A, Hamann A. Promoter polymorphisms of UCP1, UCP2, and UCP3 are not associated with diabetic microvascular complications in type 2 diabetes. Horm Metab Res 2007; 39: 306-309

49 Schwarz PE, Towers GW, Fischer S, Govindarajalu S, Schulze J, Bornstein SR, Hanefeld M, Vasseur F. Hypoadiponectinemia is associated with progression toward type 2 diabetes and genetic variation in the ADIPOQ gene promoter. Diabetes Care 2006; 29: 1645-1650 